Journal of Advanced College of Engineering and Management, Vol.4, 2018

\title{
BEARING CAPACITY ANALYSIS AND ZONING OF KATHMANDU FOR SHALLOW FOUNDATIONS
}

\author{
Ram Krishna Danai ${ }^{1}$, Indra Prasad Acharya ${ }^{2}$ \\ ${ }^{1}$ Research student, Masters in geotechnical Engineering, Pulchowk Campus \\ Email Address: rkdanai@sagarmatha.edu.np, rksharmadanai@gmail.com \\ ${ }^{2}$ Associate Professor, Coordinator, Master Program in Geotechnical Engineering, Pulchowk Campus, T.U.
}

\begin{abstract}
The bearing capacity of foundation is the primary concern in the field of geotechnical engineering. In this study numerical models are developed for each of the secondary borehole data collected around Kathmandu valley. Finite element analysis (i.e. PLAXIS 2D) is carried out using Mohr-coulomb failure criteria to represent two dimensional soil models. Foundation is aimed to model as square footing and prescribed settlement of $10 \%$ of footing width is provided to obtain corresponding bearing capacity. In plaxis, effective stress is considered as an ultimate bearing capacity. Drained behavior with axisymmetical models have been considered for soil model in plaxis software. Various soil parameters like C (Cohesion), $\gamma$ (unit weight), $\phi$ (Frictional angle), $v$ (Poison ratio), E (Elasticity) for each $1.5 \mathrm{~m}$ and $3 \mathrm{~m}$ depths have been considered in models and in theoretical approaches.
\end{abstract}

Keywords: Bearing capacity, Various Depths, Shallow foundation, Plaxis, Soil Model, and Settlement.

\section{Background}

The bearing capacity of foundation is primary need in the field of Geotechnical engineering. The loads from super structures are to be transferred to the underlying soils through foundation safely and economically. The load at which the shear failure of the soil beneath the foundation occurs is simply termed as ultimate bearing capacity of foundation. Foundation transfers the forces and moments from the super structure to the soil below such that the stresses in soil are within permissible limits and it provides stability against sliding and overturning to the super structure. It is a transition between the super structure and foundation soil. The job of a geotechnical engineer is to ensure that both foundation and soil below are safe against failure and do not experience excessive settlement.

In some other countries, bearing capacity zoning of highly urbanized cities has been done. But, in case of Nepal, no such proper maps have been prepared yet. Not only this, but also in the developed countries, people are using modern software for modeling through which calculations with more realistic results have been obtained during their researches. So, in order to apply numerical modeling as more realistic and quick approaches in this modern world for determining soil strengths, this study have been conceptualized.

In order to reduce the unplanned urbanization rate of Kathmandu valley and in order to provide planned settlement in the valley, the construction of tall and high rise buildings is being essential so, while constructing high rise and multi-storey buildings, bearing capacity of soil should be checked before construction to prevent form collapse and settlements. If bearing capacity zonation mapping could be provided then it will reduce the time and cost of project lapsed in investigations.

Bearing capacity zonation map at various depths could provide the clear view of strata encountered at various locations. Bearing capacity zonation map will facilitates the designer/Geotechnical engineer/geologist for preliminary design of foundation, feasibility study, planning of detail investigations of complex formations, estimates of future disasters related to soil failure etc., could be done. Geotechnical characteristics are obtained through detail investigations of the sites. Application 
of numerical modeling for determining bearing capacity and other parameters would make the soil more predictable and computations would be easy along with complexities like ground water table, layer wise distribution of different formation of soil etc. could be obtained.

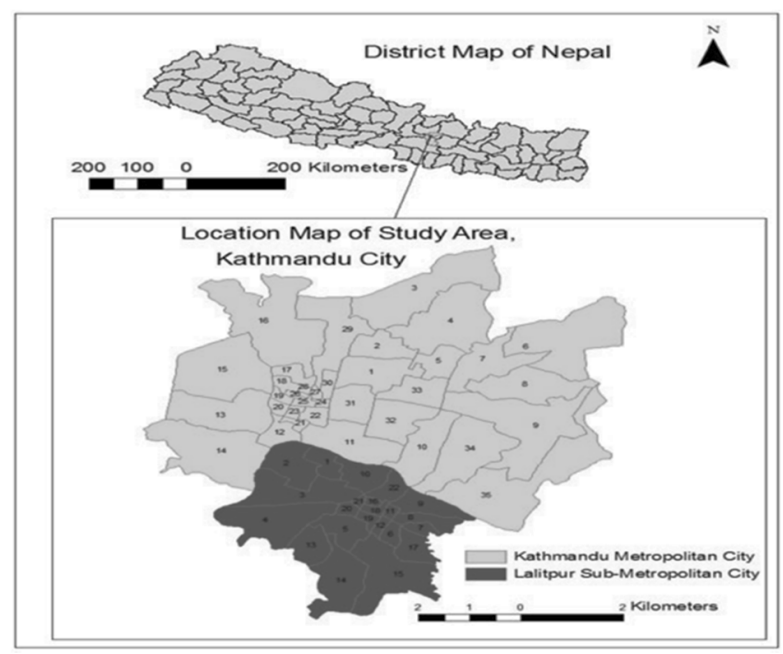

Fig.1: Borehole collection and study area

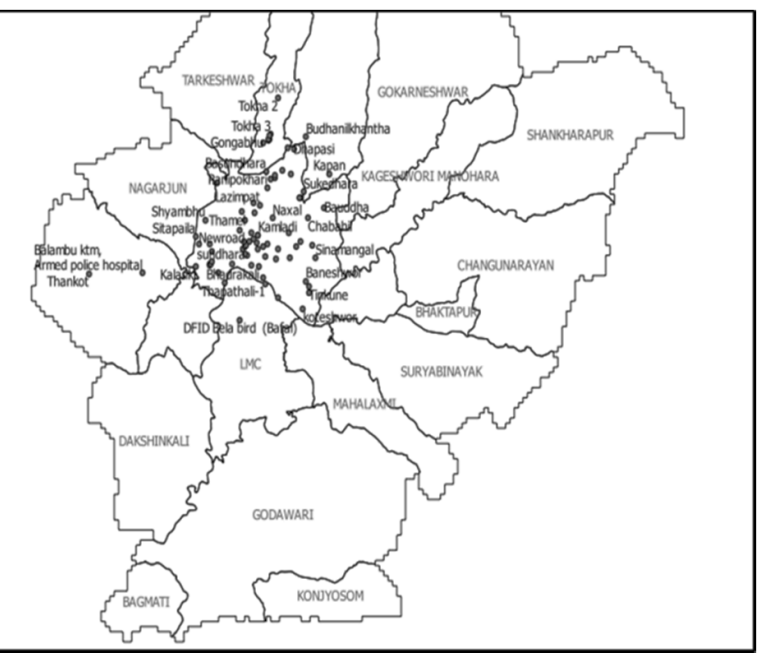

Fig.2: Digitized boreholes

The study area is Kathmandu Valley. Basically these areas are highly urbanized with high density of people. To prevent these areas from probable disasters caused by structural failures resting on soil, bearing capacity and other related parameters are evaluated.

\section{Literature Review}

The ultimate bearing capacity of shallow footings were given by traditional approaches from (Terzaghi, 1943: Meyerhof, 1951,1953,1963,1965 and 1967) including methods by Hansen (1961 and 1970) and Vesic (1973) with modification by Bowles (1996).

PLAXIS 2D has been used to estimate the bearing capacity of soil with Mohr-Coulomb's failure criteria in which medium mesh were generated. For varying D/B ratio, bearing capacity was evaluated (Fig-2), with the increase of $\mathrm{D} / \mathrm{B}$ ratio bearing capacity also increased and settlement decreased. Load settlement curve was generated for various $\mathrm{D} / \mathrm{B}=0,1,2$, [Prof. Moniuddin Md. Khajaand Mr. Vilas (2015)].

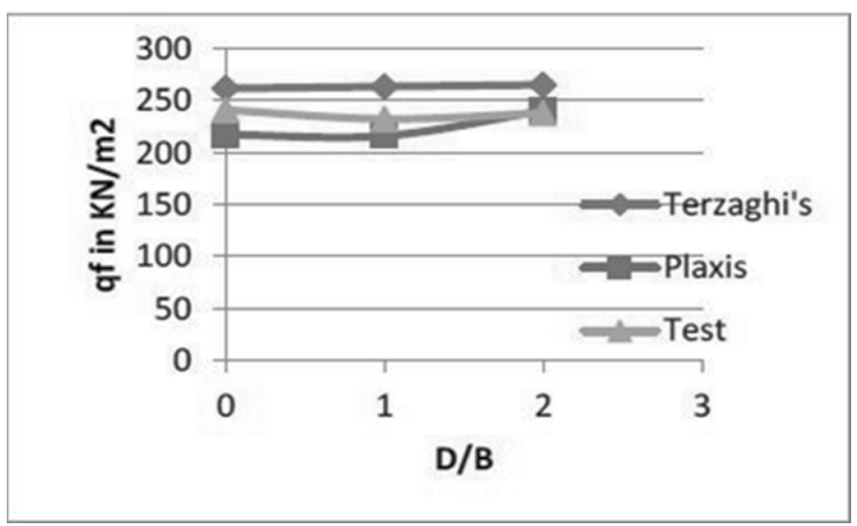

Fig. 2: Bearing Capacity from Plaxis and other approaches with varrying D/B ratios [Prof. Moniuddin Md. Khajaand Mr. Vilas (2015)].

Short term stability of footing was considered for analysis to evaluate bearing capacity of footing using FEM software, ABAQUS, citation [ Mosadegh A, Nikraz H (2015)]. 
Bearing capacity of plain-strain footing were evaluated for various friction angles $=32^{\circ}, 40^{\circ}, 48^{\circ}$. [H.J.Burd and S.Fryman (1997)].

Mapping of soil bearing capacity with varying depth were carried out in Jakarta based on N-SPT value which was used in geotechnical design [Vidayanti D. and Widyawaty N. (2016)].

Bearing capacity zoning was done based on traditional approaches from different 145 bore hole data around Kathmandu and Lalitpur districts in I.O.E, MSG Thesis [Mahto S. K. (2012)].

\section{Methodology and Materials}

The methodology includes the secondary data collection and their analysis. In this research, several steps are taken to achieve the objectives of the study. The following points show the steps that are carried out to obtain results and output of the study field.

- Collection of Study Materials.

- Collection of data from different locations (Secondary Data).

- Filtering and Interpretation of data (SPT-N values, Soil parameters).

- Modeling in Plaxis-2D software for varying parameters. I.e. depth, WT.

- Calculations of Bearing Capacities from traditional approaches.

- Data analysis and plotting the results from GIS software.

\subsection{Material Model}

The failure criterion of the soil model used in the study is assumed as Mohr-Coulomb criterion. Axisymmetric model with square footing have been considered in the model. In The research total models were prepared with varying depths of $1.5 \mathrm{~m}, 3 \mathrm{~m}, \& 4.5 \mathrm{~m}$ with various properties but here only one model have been shown for sample.

\subsubsection{Material model for soil (PLAXIS- 2D)}

Material: Soil, Gray brown medium clayey of low plasticity (ML)

Failure Criteria $=$ Mohr-coulomb

Elastic Properties:

Table 1: Model Parameters for ICT Pulchowk campus soil.

\begin{tabular}{|c|c|c|c|}
\hline Parameter & Name & Value & Unit \\
\hline Permeability in horizontal direction & $\mathrm{K}_{\mathrm{x}}$ & 1 & $\mathrm{~m} /$ day \\
\hline Permeability in vertical direction & $\mathrm{K}_{\mathrm{y}}$ & 1 & $\mathrm{~m} /$ day \\
\hline Modulus of Elasticity & $\mathrm{E}$ & 12000 & $\mathrm{kN} / \mathrm{m}^{2}$ \\
\hline Poisson's ratio & $\mathrm{C}$ & 0.3 & - \\
\hline Cohesion (constant) & $\mathrm{C}$ & 20 & $\mathrm{KN} / \mathrm{m}^{2}$ \\
\hline Friction angle & $\Phi$ & $23.72^{\circ}$ & $\mathrm{o}$ \\
\hline Dilatancy angle & $\phi$ & 0 & ${ }^{\circ}$ \\
\hline Mesh type & Fine mesh & 15 Noded & \\
\hline Parameter & Name & Value & $\mathrm{Unit}$ \\
\hline Material model & Model & Mohr-coulomb & - \\
\hline Type of material behaviour & Type & Drained & - \\
\hline Soil dry unit weight & drry & 16.3 & $\mathrm{KN} / \mathrm{m}^{3}$ \\
\hline Saturated unit weight & saturated & 19.3 & $\mathrm{KN} / \mathrm{m}^{3}$ \\
\hline
\end{tabular}




\subsubsection{Numerical model}

Various numerical models were prepared in PLAXIS-2D for different depths, different 80 locations and different types of soil around Kathmandu valley. Here sample model of only single depth $1.5 \mathrm{~m}$ have been shown below in fig 4 , fig 5 and fig 6

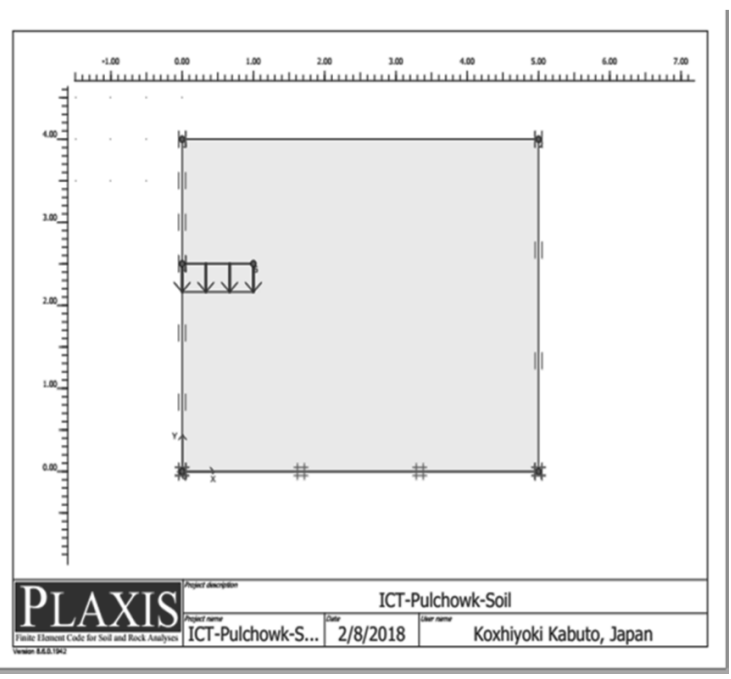

Fig: 4 Soil model at 1.5m depth in Plaxis-2D.

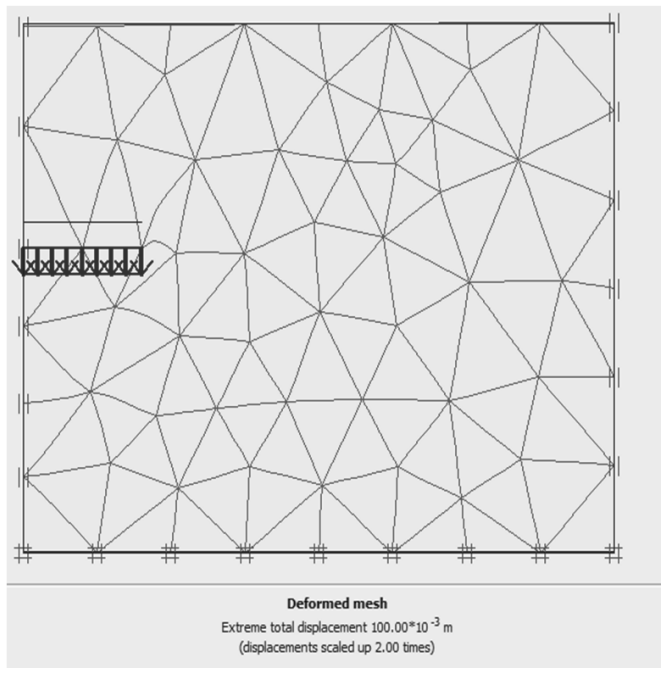

Fig. 5: Soil model obtained after deformations, deformed mesh in Plaxis-2D.

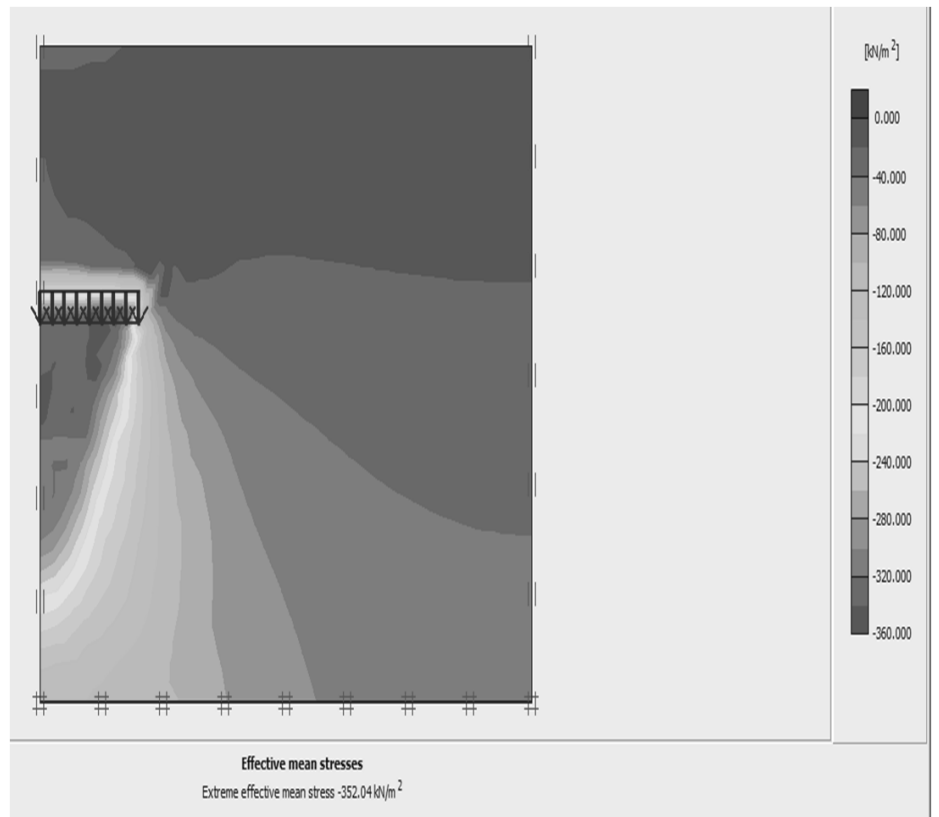

Fig. 6: Soil Model at 1.5m depth, Stress generated, Effective mean stress in Plaxis-2D

\section{Results and Discussions}

After the Bearing capacity were obtained from Models and Theoretical calculations. The least value obtained from three different methods was considered as the bearing capacity of the soil. For each two depths i.e. $1.5 \mathrm{~m}$ and $3 \mathrm{~m}$ the comparative curves were plotted to compare the values of bearing capacities with considering water table. 


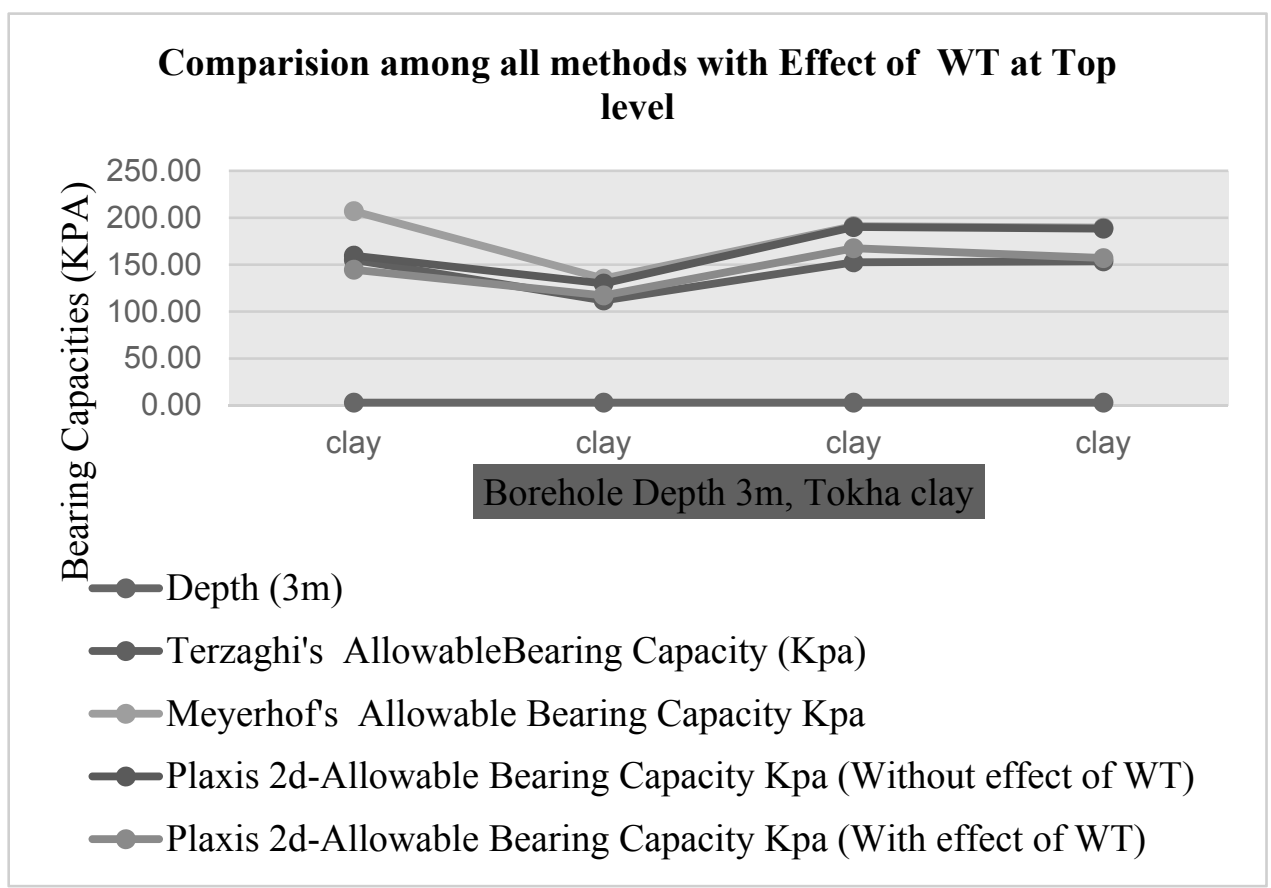

Fig 7: Comparison of bearing capacities at $3.0 \mathrm{~m}$ depth Tokha, from different methods.

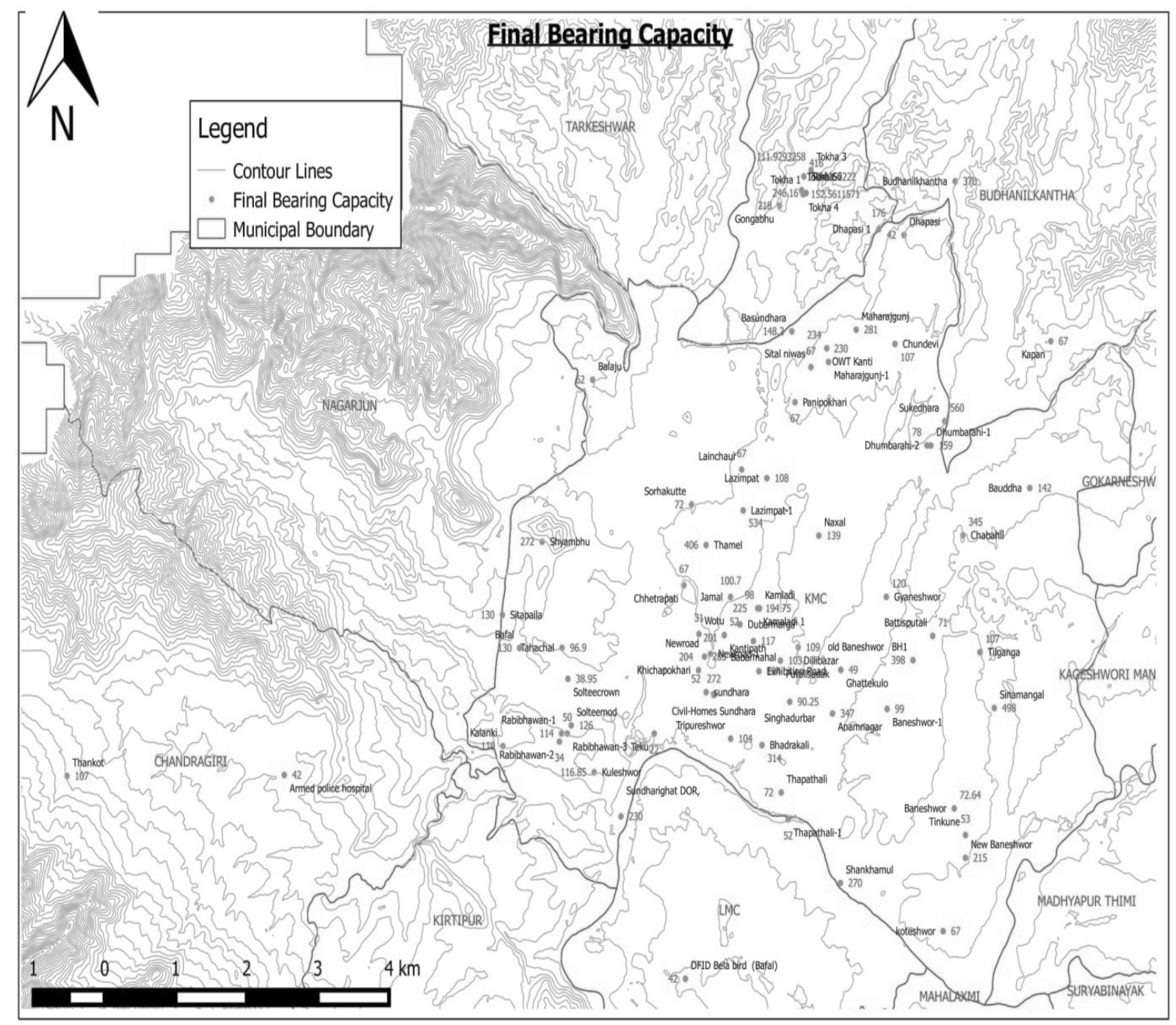

Fig. 8: Final Zonation of Bearing capacities 
Based on above results Teku, Wotu-Ktm, Rabibhawan, Soltimood, Balambu, Dhapasi, Ghatekulosemms to have low bearing capacities $(\leq 50 \mathrm{Kpa})$ which are the similar values to the hazard map produced by Department of Mines and Geology in 1998.

Additional to this some boreholes sites located near river banks seems to have low bearing capacities values and similar to those results produced by hazard map produced by Department of Mines and Geology in 1998.

\section{Conclusions}

Based on plotted results and comparisons with theoretical values of bearing capacities, all three values seem similar. Compared to theoretical values, numerical modeling values are also realistic as a result modeling gives the value of bearing capacities only in short duration and in easy manner so, numerical modeling could be used in the calculations. The variations in the result among theoretical and modeling values seem up to 5 to $15 \%$ based on types of soil and location.

\section{Recommendations}

Based on the findings of the research, following recommendations are drawn for minimizing errors while obtaining bearing capacities.

For the realistic results ground water tables should be varied according to test results obtained in the borehole logs. Comparison of bearing capacities with more theoretical approaches could give more realistic results. In this research only depth has been varied but in future researches $\mathrm{D} / \mathrm{B}$ ratio could be varied to obtain real scenarios of ground.

\section{Acknowledgements}

I wish to express my deepest and sincere appreciation to myM. Sc. Coordinator and Thesis supervisor Dr. Indra Prasad Acharya, Central Campus, Pulchowk, Institute of Engineering, Tribhuvan University, Nepal for his patient guidance, support, encouragement, and excellent advice throughout my study period.

I am also greatly indebted to Associate Professor Er.Arun Prasad Parajuli, H.O.D, Sagarmatha Engineering College, and T.U for exposing me to academic research activities and encouragement.

I wish to express my sincere gratitude to Professor Dr. Akal Bdr. Singh, I.O.E, Pulchowk campus for his guidance and valuable suggestions in all aspects during my study.

I am thankful to Department of Civil Engineering, Central Campus, Pulchowk, and Staff of M.Sc. Program in Geotechnical Engineering for their support throughout my research work.

In addition, I would like to thank all the staff of Central Material Testing Laboratory (CMTL) of Central Campus, Pulchowk, Institute of Engineering, Tribhuvan University, Nepal for helping me in obtaining data for my study. 


\section{References}

1. Bajra M. Das. "Principles of Foundation Engineering".

2. Bowles, J. E. (1977) "Foundation Analysis and Design", McGraw Hill Publications, New York.

3. Craig, R. F. (1983) "Soil Mechanics", 3rd Edition, English Language Book Society \& Vannostrand Reinhold Co. Ltd., London.

4. Das, B. M. (2007) "Principles of Foundation Engineering", Thomson India Edition, New Delhi.

5. V. G. Mutalik Desai1, Vidyasagar .V. Moogi2, "Study of Interference of Strip Footing using PLAXIS-2D” (2016).

6. IS6403-1981.

7. Knudsen B. S. and Mortensen N (2016). "Bearing Capacity, Comparison of Results from FEM and DS/EN", 1997-1 DK NA 2013.

8. Mahto S. K. (2012). "Bearing Capacity Zonation Of Urban And Sub-Urban Area of Kathmandu and Lalitpur Districts”, M.Sc thesis, Pulchowk, Lalitpur, Nepal.

9. "National Building Code of India" (1983)

10. Nujid Masyitah Md and Taha M. R. (Vol.19, 2014). "A Review of Bearing Capacity of Shallow Foundations on Clay layered soils using Numerical Method".

11. Moniuddin Md. Khajaand, Vilas (2015). "Finite Element Analysis of Soil Bearing Capacity Using Plaxis". IJERT

12. PLAXIS-2D manual 8.2, 8.6.

13. Punmia, B. C. (2005) "Soil Mechanics and Foundations", Laxmi Publications Pvt. Ltd., Bangalore

14. Salahudeen1 B. A. And Sadeeq 2. J.A. "Evaluation of Bearing Capacity and Settlement Of Foundations".

15. Som, N. N. and Das, S. C. (2003). "Theory and Practice of Foundation Design”, Prentice Hall of India, New Delhi.

16. Vidayanti D. and Widyawaty N. (2016). "The Mapping of Soil Bearing Capacity and The Depth of Hard Stratum for Supporting Pile Based On N-spt Value in Jakarta".

17. O.M Shrestha et.al. (1998, first edition) "Engineering And Geological Map of The Kathmandu Valley" 